\title{
Refractory myasthenia gravis, dysphagia and malnutrition: A case report to suggest disease-specific nutritional issues
}

\author{
Emanuele Cereda, M.D. ${ }^{\mathrm{a}, *}$, Dario Beltramolli, M.D. ${ }^{\mathrm{b}}$, Carlo Pedrolli, M.D. ${ }^{\mathrm{b}}$, \\ and Antonio Costa, M.D. ${ }^{\mathrm{b}}$ \\ ${ }^{a}$ International Center for the Assessment of Nutritional Status (ICANS), University of Milan, Italy \\ ${ }^{b}$ Dietetic and Clinical Nutrition Unit, Trento Hospital, Trento, Italy \\ Manuscript received September 17, 2008; accepted December 14, 2008
}

\begin{abstract}
Objective: We describe a case of refractory myasthenia gravis with bulbar involvement and the nutritional treatment solutions proposed to treat the associated dysphagia and malnutrition.

Methods: A 39-y-old woman with refractory myasthenia gravis was referred to our clinical nutrition unit for deteriorating dysphagia and progressive malnutrition.

Results: The first-line nutritional approach consisted of dietary counseling and thickened meals. Unfortunately, no adequate oral intake was achieved and an enteral nutrition treatment was proposed. A nasogastric tube was removed after a few days due to local pain and poor quality of life. Despite consistent weight loss and overt malnutrition, the patient refused percutaneous endoscopic gastrostomy placement. Neurologic symptoms did not show any improvement but unexpectedly the patient's weight started to increase to previous values. Anamnestic recall revealed that the patient learned by herself how to position the nasogastric tube that is now temporarily used for formula infusion coinciding with neurologic poussés.

Conclusions: Current guidelines consider chronic neurologic diseases with associated dysphagia, where refractory myesthania gravis has also been considered, a unique category. Chronic neurogenic dysphagia with high risk of aspiration, long-term inability to obtain adequate oral intakes, and malnutrition are established indications for percutaneous endoscopic gastrostomy placement. However, patients may need different forms of nutritional intervention during the course of their illness and choices and indications should contemplate ethical reasons, clinical benefits, minimal risks, and acceptable quality of life. Minimally invasive intermittent enteral nutrition might be considered a possible clue for nutritional management of exacerbating dysphagia. (c) 2009 Elsevier Inc. All rights reserved.
\end{abstract}

Keywords: $\quad$ Myasthenia gravis; Dysphagia; Malnutrition; Enteral feeding; Percutaneous endoscopic gastrostomy; Quality of life

\section{Case report}

In April 2006, a 39-y-old woman was referred to our clinical nutrition unit for deteriorating dysphagia and malnutrition in the course of myasthenia gravis (MG) exacerbations. Her clinical history included Graves-Basedow disease, uterine fibromyoma causing chronic anemia, anxious-depressive syndrome, and other different neoplastic diseases (squamous cell carcinoma of the soft palate, left-foot melanoma, vocal chord polypus) that were treated with \footnotetext{
16077.

*Corresponding author. Tel.: +39-02-503-16079; fax: +39-02-503-

E-mail address: emanuele.cereda@virgilio.it (E. Cereda).
}

a surgical procedure. MG (presence of acetylcholine receptor-specific autoantibodies and a primary postsynaptic neuromuscular junctional disorder by electrophysiologic testing) [1-3] was first diagnosed in August 2005. Computed tomogram of the chest revealed the presence of mediastinal thymic residuals. The patient was treated with oral anticholinesterase therapy (pyridostigmine bromide) and a thymectomy was performed (Table 1). Unfortunately, despite initial improvement of neurologic manifestations, no long-lasting benefits were achieved. The disease assumed a refractory course with more and more frequent exacerbations that progressively required increasing doses of immunosuppressant (corticosteroids followed by azathioprine), frequent visits for plasmapheresis (in the case of a myasthenic crisis, about 


\begin{tabular}{|c|c|c|c|c|c|c|c|}
\hline & August 2005 & April 2006 & July 2006 & October 2006 & January 2007 & April 2007 & August 2008 \\
\hline Weight (kg) & 57 & 53.3 & 49.7 & 41.0 & 51.4 & 54.8 & 56.8 \\
\hline $\operatorname{BMI}\left(\mathrm{kg} / \mathrm{m}^{2}\right)$ & 25.0 & 23.3 & 21.8 & 17.9 & 22.5 & 24.0 & 24.9 \\
\hline WL (\%) & - & -6.5 & -12.8 & -28.0 & -9.8 & -3.8 & -0.3 \\
\hline $\operatorname{MUAC}(\mathrm{cm})^{*}$ & - & $29.2(50)$ & $24.5(10-25)$ & $20.1(<5)$ & $25.3(10)$ & $28.2(25-50)$ & $28.3(25-50)$ \\
\hline $\operatorname{TSF}(\mathrm{mm})^{*}$ & - & $15.5(10-25)$ & $13.2(5-10)$ & $7.8(<5)$ & $15.1(10-25)$ & $19.6(25-30)$ & $18.8(25-30)$ \\
\hline AMA $\left(\mathrm{cm}^{2}\right)^{*}$ & - & $47.1(\sim 80)$ & $32.9(\sim 25)$ & $24.8(<5)$ & $33.6(\sim 25)$ & $38.6(50)$ & $39.9(55-60)$ \\
\hline $\mathrm{BP}(\mathrm{mmHg})$ & $135 / 85$ & $120 / 80$ & $105 / 70$ & $90 / 65$ & $110 / 70$ & $110 / 75$ & $120 / 80$ \\
\hline $\mathrm{Hb}(\mathrm{g} / \mathrm{L})$ & 12,7 & 11.9 & 13.5 & 10.1 & 10.9 & 12 & 12.1 \\
\hline MCV (fL) & - & 77.3 & 73.5 & 63.9 & 65.5 & 70.6 & 76.5 \\
\hline $\operatorname{TLC}\left(/ \mathrm{mm}^{3}\right)$ & - & 1650 & 1296 & 1028 & 1551 & 1989 & 1978 \\
\hline Iron $(\mathrm{mg} / \mathrm{dL})$ & - & 81 & 102 & 29 & 39 & 80 & 85 \\
\hline Albumin $(\mathrm{g} / \mathrm{L})$ & - & 44 & 41 & 35 & 40 & 42 & 41 \\
\hline $\mathrm{TC}(\mathrm{mg} / \mathrm{dL})$ & - & 152 & 133 & - & 156 & - & 149 \\
\hline $\mathrm{TG}(\mathrm{mg} / \mathrm{dL})$ & - & 75 & 64 & - & 74 & - & 78 \\
\hline Glucose (mg/dL) & - & 88 & 80 & 85 & 86 & 92 & 89 \\
\hline $\begin{array}{l}\text { Prevalent neurologic } \\
\text { symptoms } \\
\text { (new onset) }\end{array}$ & $\begin{array}{l}\text { Weakness, anserine } \\
\text { gait, asymmetric } \\
\text { ptosis, chewing and } \\
\text { swallowing } \\
\text { difficulties }\end{array}$ & $\begin{array}{l}\text { Bulbar weakness } \\
\text { with hoarseness, } \\
\text { nasal speech } \\
\text { and liquid dysphagia }\end{array}$ & $\begin{array}{l}\text { Dysarthria, total } \\
\text { dysphagia, } \\
\text { with nasal } \\
\text { regurgitation }\end{array}$ & $\begin{array}{l}\text { Neck flexor } \\
\text { weakness, } \\
\text { marked } \\
\text { limb weakness, } \\
\text { smaller lung } \\
\text { volumes }\end{array}$ & $\begin{array}{l}\text { Assisted walking, } \\
\text { diplopia } \\
\text { weakness, } \\
\text { hypophonia, } \\
\text { dyspnea }\end{array}$ & \multicolumn{2}{|c|}{$\begin{array}{l}\text { Increased susceptibility to exacerbations } \\
\text { despite in-course treatments }\end{array}$} \\
\hline \multirow[t]{6}{*}{$\begin{array}{l}\text { Pharmacologic } \\
\text { treatment } \\
\text { of myasthenia }\end{array}$} & $\begin{array}{l}\text { Pyridostigmine } \\
\text { bromide } \\
300 \mathrm{mg} \\
+180 \mathrm{R} / \mathrm{d} \rightarrow \\
\text { Thymectomy } \\
\text { performed } \\
\text { in January } \\
2006\end{array}$ & $\begin{array}{l}\text { Pyridostigmine } \\
\text { bromide } \\
450 \mathrm{mg}+ \\
\quad 180 \mathrm{R} / \mathrm{d} \rightarrow \\
+\end{array}$ & $\begin{array}{l}\text { Pyridostigmine } \\
\text { bromide } \\
555 \mathrm{mg}+ \\
180 \mathrm{R} / \mathrm{d} \rightarrow\end{array}$ & $\begin{array}{l}\text { Pyridostigmine } \\
\text { bromide } \\
300 \mathrm{mg} \\
+180 \mathrm{R} / \mathrm{d} \rightarrow\end{array}$ & As previous $\rightarrow$ & As previous $\rightarrow$ & As previous \\
\hline & & $\begin{array}{l}\text { Steroids } \\
\quad 50 \mathrm{mg} / \mathrm{d} \rightarrow \\
+\quad\end{array}$ & $\begin{array}{l}\text { Steroids } \\
\quad 75 \mathrm{mg} / \mathrm{d} \rightarrow\end{array}$ & $\begin{array}{l}\text { Steroids } \\
\quad 50 \mathrm{mg} / \mathrm{d} \rightarrow\end{array}$ & As previous $\rightarrow$ & Steroids $75 \mathrm{mg} / \mathrm{d} \rightarrow$ & $\begin{array}{l}\text { Steroids } \\
\quad 75 \mathrm{mg} / \mathrm{d}\end{array}$ \\
\hline & & $\begin{array}{l}\mathrm{PE} / 3 \mathrm{mo} \rightarrow \\
+\end{array}$ & As previous $\rightarrow$ & As previous $\rightarrow$ & As previous $\rightarrow$ & As previous $\rightarrow$ & As previous \\
\hline & & Ig-IV/3 mo & As previous $\rightarrow$ & $\begin{array}{l}\text { As previous } \rightarrow \\
+\end{array}$ & $\mathrm{Ig}-\mathrm{IV} / 2 \mathrm{mo}$ & As previous $\rightarrow$ & Monthly \\
\hline & & & & $\begin{array}{l}\text { Azathioprine } \\
150 \mathrm{mg} / \mathrm{d}\end{array}$ & As previous $\rightarrow$ & As previous $\rightarrow$ & As previous \\
\hline & & & & & $\begin{array}{l}+ \\
\text { Inhaled broncho- } \\
\quad \text { dilator } 2 \times / \mathrm{d}\end{array}$ & As previous $\rightarrow$ & As previous \\
\hline
\end{tabular}


$3 \mathrm{mo}$ ), and the use of regular intravenous immunoglobulins (Ig-IV) that the patient currently uses once a month (for disease course and treatment adjustments, see Table 1). Up to January 2006, body weight was stable ( $57 \mathrm{~kg}$, body mass index [BMI] $25 \mathrm{~kg} / \mathrm{m}^{2}$ ) and simple dietary advice (for a "soft" diet) showed efficacy in coping with chewing and swallowing difficulties. The more consistent bulbar involvement led to liquid followed by total dysphagia. At admission (April 2006) to our unit significant weight loss $(\sim 6.5 \%$ in the previous $3 \mathrm{mo}$ ) was already recordable. In the first instance, the use of oral nutritional supplements and of thickening agents was prescribed but the rapid worsening of both clinical conditions (further 6\% weight loss) and neurologic symptoms and the high risk of aspiration indicated enteral nutrition (July 2006) [4-7]. Accordingly, a nasogastric tube was positioned and home delivery of the infusion equipment was planned. Initial therapy consisted of an infusion of $1000 \mathrm{~mL}$ of a polymeric hypercaloric formula $(1.5 \mathrm{kcal} /$ $\left.\mathrm{mL} ; \sim 1500 \mathrm{kcal} / \mathrm{d}\left[30 \mathrm{kcal} \cdot \mathrm{kg}^{-1} \cdot \mathrm{d}^{-1}\right]\right)$. In agreement with the patient, the choice of this type of support was made to obtain effective nutritional repletion and to maintain an acceptable quality of life (QOL). After an adequate period of enteral nutrition induction, with a progressive increase of the amount of formula to be infused hourly, overall support was planned to take place during the night, thus allowing for good management of activities of daily living. However, after a few days the tube was removed due to poor toleration. The patient complained of a local pain in the inner nose and above all the "unacceptable prospect of constantly appearing to have a trunk." Then overt malnutrition occurred (October 2006, BMI $17,9 \mathrm{~kg} / \mathrm{m}^{2}$, total weight loss $-28 \%$ of initial body weight) and different, but not life-threatening, episodes of aspiration with cough were reported. A percutaneous endoscopic gastrostomy was proposed but was refused. She could not accept "the presence of a foreign body" and to have a constant sign of her disease even in period of fair compensation (under therapeutic control). Neurologic symptoms did not show any improvement but unexpectedly the patient's weight started to increase to previous values and, only after 6 mo, anamnestic recall revealed that the patient learned by herself how to position the nasogastric tube and to feed. In particular, she modified the positioning technique as follows: she introduced a lubricated (petroleum oil) 12-Fr feeding tube in the nose until she felt it touching the throat. Then she pushed it while swallowing to introduce it until the mark was reached but without checking the correct placement (e.g., aspiration of a sample of gastric content and a check of the $\mathrm{pH}$ with a litmus paper). The patient opted for overnight feeding $(1000 \mathrm{~mL}$ of a polymeric hypercaloric formula, up to $140 \mathrm{~mL} / \mathrm{h}$ from $13: 00$ to $07: 00 \mathrm{~h}$, $\sim 35 \mathrm{kcal} \cdot \mathrm{kg}^{-1} \cdot \mathrm{d}^{-1}$ ) and to remove the tube at the end of each infusion. In addition, she refused our assistance but accepted advice on how to check the correct placement. From January 2007 to August 2008 she positioned the feeding tube for about $7-10 \mathrm{~d} / \mathrm{mo}$ according to disease exacerbations, thus maintaining her weight for about 8 mo (January 2008 to 


\section{NUTRITIONAL MANAGEMENT OF NEUROGENIC DYSPHAGIA}

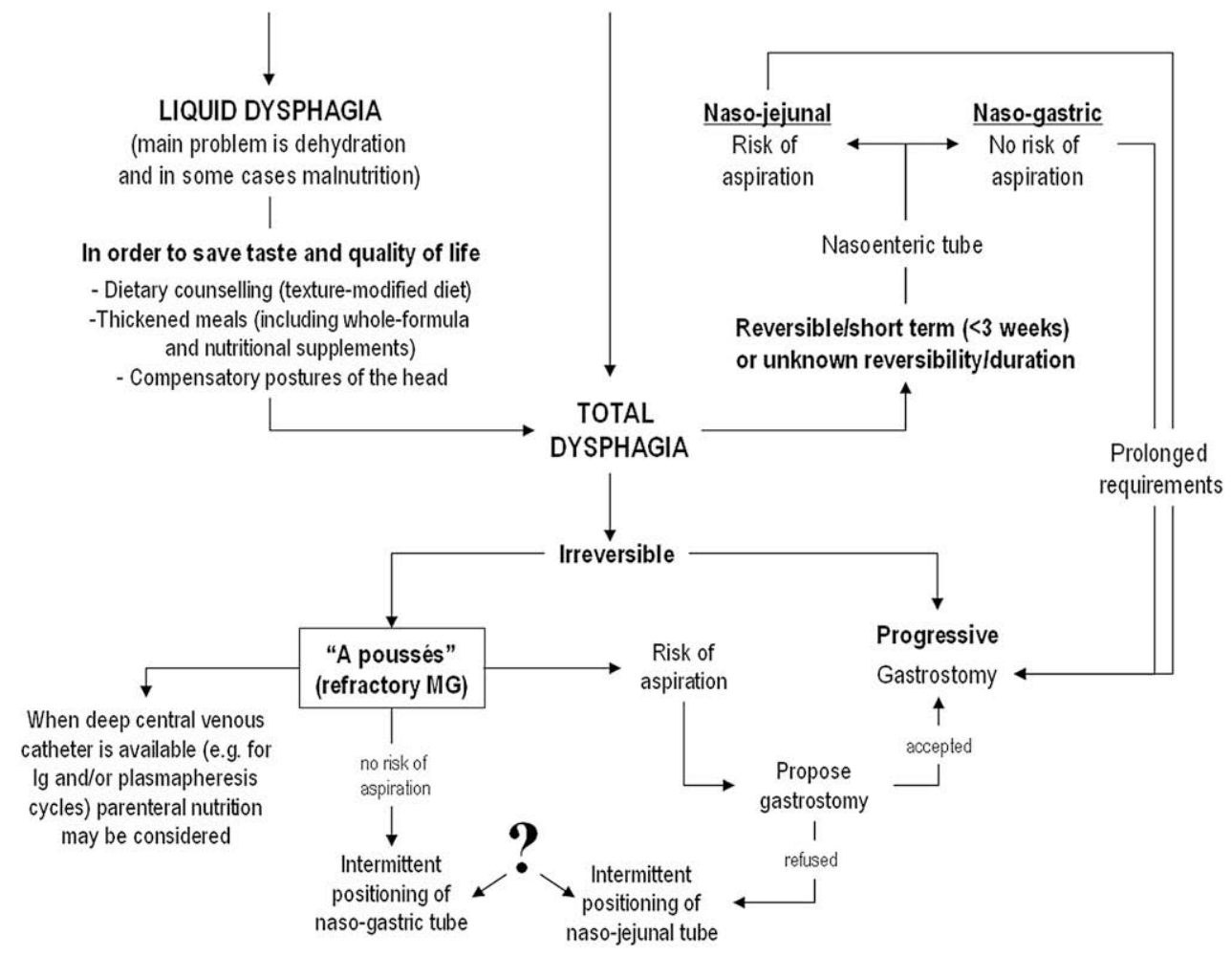

Fig. 1. Hypothetical decision tree for nutritional treatment of MG and neurogenic dysphagia [6]. MG, myasthenia gravis.

August 2008; for the course of nutritional, anthropometric, and biochemical parameters, see Table 1).

Given the current frequency of plasmapheresis and Ig-IV cycles, placement of a deep central venous catheter to administer the treatments has been considered and the use of total parenteral nutrition might be hypothesized. However, the patient's acceptance and the actual feasibility of the procedure have not yet been tested.

\section{Discussion}

Myesthenia grave is a rare (prevalence 1-2 in 5000) autoimmune disease of the neuromuscular junction due to the presence of acetylcholine receptor-specific or musclespecific tyrosine kinase autoantibodies, which translates to the typical weakness and fatigue [1-3].

With regard to clinical presentation, in about two-thirds of patients, the initial deficit involves extrinsic ocular muscles but in only $10 \%$ of cases do symptoms remain limited to this area (ocular MG). Usually, fluctuating and fatigable weakness progressively generalizes to other muscle groups until the occasional lethal involvement of the respiratory muscle group. Bulbar muscles can also be affected. In such a case, oropharyngeal weakness results in a fall of the soft palate with nasal speech and possible liquid regurgitation during swallowing or overt dysphagia, whereas laryngeal involvement is associated with hoarseness, dysarthria, incom- plete glottic closure, and an increased risk of aspiration. In any case, the evolution, even in relation to different responses to available treatments, is unpredictable, thus passing from mild and reversible to a refractory disease condition with occasional or regular exacerbations as in the present case. Accordingly, treatment must be individualized to obtain maximum improvement of neuromuscular function and minimum adverse effects and take into account a patient's ability to comply with drug use and doses $[3,8]$.

However, not only pharmacologic but also nutritional treatments should be considered in disease management, but, so far, little attention seems to be given to this issue. Poor nutritional status, as described by a low BMI and muscle protein (arm muscle area) and body weight losses, is consistently associated with adverse outcomes (e.g., mortality, infections) and chronic neurologic diseases are know to negatively affect adequate energy intake [5,6]. Indeed, there is no study describing possible changes of nutritional status in patients with MG. In addition, it was inappropriate to include MG among chronic neurologic diseases in which the final treatment is frequently percutaneous gastrostomy [5-7]. Nevertheless, nutritional treatment also should be individualized according to pharmacologic treatment response. Patients may need different forms of nutritional intervention (Fig. 1) during the course of their illness and choices and indications should contemplate nutritional risk, ethical reasons, adequate clinical benefits, minimal risks, and an acceptable 
QOL $[6,7,9]$. This might be emphasized for MG in which neurologic symptoms with nutritional aspects present and progress differently from one case to another. Further, other overlapping conditions might affect a patient's swallowing ability (e.g., Graves-Basedow disease, squamous cell carcinoma of the soft palate, and vocal cord polyp) and interest in food (e.g., depression) and should be taken into account during a patient's assessment. Moreover, although the refractory form seems like an irreversible disease, the course is generally a poussés, with exacerbations alternating with periods of fair compensation resulting from cycles of plasmapheresis and Ig-IV.

In the initial stages, patients might present only mild chewing difficulties due to closure muscle weakness and fatigability, and the use of consistency-modified diets or the choice of certain food rather than others and compensatory postures of the head may be sufficient to remedy the problem [7]. Moreover, the use of oral nutritional supplements should always be considered when protein-calorie needs are not reached and/or nutrition-related risk is recorded $[4,10]$. In other cases, overt dysphagia might be the next step or occur from the outset or be the only isolated symptom [11]. This condition is currently recognized as manageable and, when effective management is implemented, an improved QOL can result. In this regard, adequate diagnosing is least beneficial and different techniques are currently available. When motor and non-motor disorders are suspected, manometry, fiber-optic endoscopy, and electromyography are valid assessment tools, are widely available in a hospital setting, and should be regarded as complementary $[7,12,13]$. However, despite being effective and accurate, videofluorography and videofluoroscopy with concomitant Tensilon testing are less available, more expensive, require trained personnel, and have been found to be unsuitable for routine use due to radiation exposure $[7,11]$. The potential value of novel techniques, such as scintigraphy, impedance pharyngography, or simple acoustic devices, has never been investigated in subjects with MG.

When prevalent liquid dysphagia is detected, the most important potential consequences are dehydration and aspiration. Accordingly, the use of jelly-water allows the maintenance of a positive body-water balance, QOL, and lower risk of aspiration. However, when solid/complete dysphagia occurs, consistent protein-calorie deficit and subsequent malnutrition also should be considered. In the present case, consistent weight loss $(>10 \%$ in the previous $3 \mathrm{mo})$ toward malnutrition (BMI $<18.5 \mathrm{~kg} / \mathrm{m}^{2}$ ) and evident alteration of nutritional markers (e.g., albumin level $<35 \mathrm{~g} / \mathrm{L}$, total lymphocyte count $<1500 / \mathrm{mm}^{3}$ ) clearly suggested a high risk of nutrition-related health complications [14] (Table 1). In such a case, thanks to the efforts of commercial clinical nutrition companies, safe and effective nutritional repletion can be initially achieved not only through a consistency-modified diet and thickened meals but also through the use of whole formulations and ready-to-eat foods that retain the appearance and flavor of the original and enable food enjoyment and QOL to be addressed [7]. In contrast, chronic neurogenic dysphagia with a high risk of aspiration, a long-term inability to obtain adequate oral intakes, and concomitant malnutrition are the most common and established indications for gastrostomy $[5,6]$ but " $\ldots$ prior to the insertion of an enteral feeding tube, each case should be considered on its own merits, taking into account the clinical situation, diagnosis, prognosis, ethical issues, the expected effect on the patient's quality of life and the patient's own wishes..."[6]. The present case is a good example to reflect on the application of guidelines. Indeed, a patient's willingness is out of the question. However, the clinical situation and QOL become a matter for discussion. Although placement of a gastrostomy tube would have offered consistent clinical benefits, our experience demonstrates that in refractory MG the typical nutritional approach usually regarded for the majority of chronic neurologic diseases may sometimes be too aggressive. Thus, in agreement with the ethical issue, all options available to us must be considered. Eventually, also an intermittent enteral nutrition (e.g., for $10 \mathrm{~d}$ ) that appears to be effective and suitable for a poussés chronic disease in which the initial drug response allows a patient to maintain food enjoyment and QOL until the next exacerbation. Unfortunately, current guidelines consider chronic neurologic diseases with associated dysphagia, where refractory MG has also been considered, a unique category and gastrostomy as been indicated $[4,6]$. However, we believe that in MG QOL could be maintained longer and with higher values than those of other irreversible disorders (e.g., bulbar paralysis, cerebral palsy, amyotrophic lateral sclerosis, brain tumor, multiple sclerosis, Alzheimer's and Parkinson's diseases). In addition, intermittent enteral nutrition is no longer contemplated $[4,6]$, probably in relation to major limitations such as monitoring, compliance, and safety.

In some cases, if a central venous catheter is available for other purposes (e.g., plasma exchange and/or Ig-IV cycles), parenteral nutrition also might be considered to provide nutritional support but major complications associated with its use and the need for proper care of this route should be always kept in balance $[4,15]$.

However, despite appearing feasible by highly compliant patients and with manual skills, the self-positioning of a nasogastric tube is a practice that should be probably discouraged in view of the high risk of incorrect placement (e.g., airways or too high in the esophagus) and aspiration, with subsequent ingested pneumonia.

Although this practice would not probably sound new to clinical nutritionists, including ourselves, to the best of our knowledge, this is the first case to be reported in the literature.

Timely multidisciplinary (neurologic and nutritional) approaches to a patient with chronic neurologic diseases is strongly recommended.

\section{References}

[1] Vincent A. Unravelling the pathogenesis of myasthenia gravis. Nat Rev Immunol 2002;2:797-804.

[2] Conti-Fine BM, Milani M, Kaminski HJ. Myasthenia gravis: past, present, and future. J Clin Invest 2006;116:2843-54. 
[3] Juel VC, Massey JM. Myasthenia gravis. Orphanet J Rare Dis 2007; 2:44.

[4] ASPEN Board of Directors and the Clinical Guidelines Task Force. Guidelines for the use of parenteral and enteral nutrition in adult and pediatric patients. JPEN 2002;26(suppl):1SA-138.

[5] Gencosmanoglu R. Percutaneous endoscopic gastrostomy: a safe and effective bridge for enteral nutrition in neurological or non-neurological conditions. Neurocrit Care 2004;1:309-17.

[6] Löser C, Aschl G, Hébuterne X, Mathus-Vliegen EM, Muscaritoli M, Niv Y, et al. ESPEN guidelines on artificial enteral nutrition-percutaneous endoscopic gastrostomy (PEG). Clin Nutr 2005;24:848-61.

[7] Lister R. Oropharyngeal dysphagia and nutritional management. Curr Opin Gastroenterol 2006;22:341-6.

[8] García-Carrasco M, Escárcega RO, Fuentes-Alexandro S, Riebeling C, Cervera R. Therapeutic options in autoimmune myasthenia gravis. Autoimmun Rev 2007;6:373-8.

[9] Howard P, Jonkers-Schuitema C, Furniss L, Kyle U, Muehlebach S, Odlund-Olin A, et al. Managing the patient journey through enteral nutritional care. Clin Nutr 2006;25:187-95.
[10] Baldwin C, Weekes CE. Dietary advice for illness-related malnutrition in adults. Cochrane Database Syst Rev 2008;1:CD002008.

[11] McIntyre K, McVaugh-Smock S, Mourad O. An adult patient with new-onset dysphagia. CMAJ 2006; 175:1203.

[12] Ertekin C, Yüceyar N, Aydogdu I. Clinical and electrophysiological evaluation of dysphagia in myasthenia gravis. J Neurol Neurosurg Psychiatry 1998;65:848-56.

[13] Oda AL, Chiappetta AL, Annes M, Marchesan IQ, Oliveira AS. Clinical, endoscopical and manometric evaluation of swallowing in patients with acquired autoimmune myasthenia gravis. Arq Neuropsiquiatr 2002;60:986-95.

[14] Seltzer MH, Bastidas JA, Cooper DM, Engler P, Slocum B, Fletcher HS. Instant nutritional assessment. JPEN 1979;3:157-9.

[15] Bozzetti F, Mariani L, Bertinet DB, Chiavenna G, Crose N, De Cicco M, et al. Central venous catheter complications in 447 patients on home parenteral nutrition: an analysis of over 100.000 catheter days. Clin Nutr 2002;21:475-85.

[16] Frisancho AR. New norms of upper limb fat and muscle areas for assessment of nutritional status. Am J Clin Nutr 1981;34:2540-5. 